This is the author's final, peer-reviewed manuscript as accepted for publication. The publisher-formatted version may be available through the publisher's web site or your institution's library.

\title{
Registration of near-isogenic winter wheat germplasm contrasting in Fhb1 for Fusarium head blight resistance
}

Amy Bernardo, Guihua Bai, Jianbin Yu, Fred Kolb, William Bockus, and Yanhong Dong

\section{How to cite this manuscript}

If you make reference to this version of the manuscript, use the following information:

Bernardo, A., Bai, G., Yu, J., Kolb, F., Bockus, W., \& Dong, Y. (2014). Registration of near-isogenic winter wheat germplasm contrasting in Fhb1 for Fusarium head blight resistance. Retrieved from http://krex.ksu.edu

\section{Published Version Information}

Citation: Bernardo, A., Bai, G., Yu, J., Kolb, F., Bockus, W., \& Dong, Y. (2014).

Registration of near-isogenic winter wheat germplasm contrasting in Fhb1 for Fusarium head blight resistance. Journal of Plant Registrations, 8(1), 106-108.

Copyright: Copyright $\odot$ Crop Science Society of America.

Digital Object Identifier (DOI): doi:10.3198/jpr2013.05.0021crgs

Publisher's Link:

https://www.crops.org/publications/jpr/articles/8/1/106?highlight=\&search-result=1

This item was retrieved from the K-State Research Exchange (K-REx), the institutional repository of Kansas State University. K-REx is available at http://krex.ksu.edu 
Registration of Near-Isogenic Winter Wheat Germplasm Contrasting in Fhb1 for Fusarium Head Blight Resistance

Amy Bernardo ${ }^{1}$, Guihua Bai ${ }^{2,3}$, Jianbin $\mathrm{Yu}^{2}$, Fred Kolb ${ }^{4}$, William Bockus ${ }^{1}$, and Yanhong Dong ${ }^{5}$

${ }^{1}$ Dept. of Plant Pathology and ${ }^{2}$ Dept. of Agronomy, Kansas State University, and ${ }^{3}$ ARS-USDA, Hard Winter Wheat Genetics Research Unit, Manhattan, KS; ${ }^{4}$ Dept. of Crop Sciences, University of Illinois, Urbana, IL; and ${ }^{5}$ Dept. of Plant Pathology, University of Minnesota, St. Paul, MN

*Corresponding author (guihua.bai@usda.ars.gov). 


\begin{abstract}
The Chinese wheat Ning7840 (Triticum aestivum L.) contains Fhb1, a major quantitative trait locus (QTL) for Fusarium head blight (FHB) resistance, and has been widely used as a resistant parent in breeding programs worldwide, but due to its poor adaptation in the US, its progenies usually exhibit reduced grain yield due to the transfer of undesirable genes from Ning7840. The development of five near-isogenic lines (NILs, 'Clark’*7/Ning7840) (NIL75, Reg. No. GP--, PI--; NIL78, Reg. No. GP--, PI---; NIL80, Reg. No. GP--, PI---; NIL90, Reg. No. GP--, PI---, NIL98, Reg. No. GP--, PI---) contrasting in Fhb1 alleles was intended to overcome this potential limitation. Marker-assisted backcrossing was used to develop the NILs. Approximately 2000 $\mathrm{BC}_{7} \mathrm{~F}_{2}$ plants from the backcross of Ning7840 by Clark (recurrent parent) were screened with

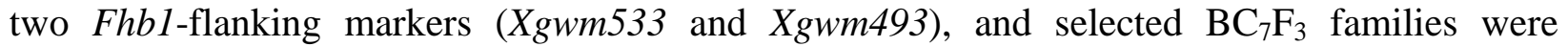
evaluated for FHB resistance in greenhouses. Both genotypic and phenotypic data confirm the presence of Fhb1 in the four resistant NILs and absence in the one susceptible NIL. All resistant NILs had significantly higher FHB resistance and lower deoxynivalenol (DON) content than Clark and the susceptible NIL but yield similar to Clark $(P=0.295)$. Marker-assisted backcross efficiently transferred Fhb1 into US hard winter wheat without transferring undesirable traits from Ning7840, and these Fhb1 NILs should be useful parents for effective use of Fhb1 in US winter wheat.
\end{abstract}

Abbreviations: FHB, Fusarium head blight; QTL, quantitative trait locus; PI, plant introduction; NIL, near-isogenic line; PSS, proportion of symptomatic spikelets; KS, Kansas; IL, Illinois 


\section{Introduction}

Fusarium head blight (FHB, caused by Fusarium graminearum Schwabe; teleomorph Gibberella zeae [Schwein.:Fr.] Petch) is a destructive disease that reduces wheat (Triticum aestivum L.) grain yield and quality. Breeding varieties with FHB resistance is the most effective approach to controlling FHB. Resistance to spread of disease within a spike (Type II resistance) is considered a stable form of FHB resistance, and Fhb1 on chromosome 3BS is the major quantitative trait locus (QTL) governing Type II resistance (reviewed by Buerstmayr et al., 2009). Ning7840, a derivative of Sumai3, has a high level of Type II resistance, and its Fhb1 explains as much as $53 \%$ of phenotypic variation in segregating populations (Bai et al., 1999; Liu et al., 2009). In addition, Ning7840 is resistant to leaf (Puccinia triticina Eriks.) and stripe (Puccinia striiformis f. sp. tritici) rusts and powdery mildew (Blumeria graminis f. sp. tritici) and has better agronomic characteristics than Sumai3 (Bai et al., 1989). For these reasons, Ning7840 has been used frequently as a source of resistance in breeding programs (Lu and Wang, 1991); however, the direct use of unadapted Ning7840 as a resistant parent in US breeding programs often results in grain yield reduction. Breaking the association between Fhb1 and other unadapted traits is critical for successful use of Fhb1 in US winter wheat breeding programs. Here we report the development and characterization of near-isogenic lines (NILs) carrying Fhb1 in US-adapted winter wheat cultivar 'Clark'.

\section{Materials and Methods}

Ning7840 (Aurora/Anhui11//Sumai 3) is a hard red facultative Chinese elite breeding line that carries Fhb1 and shows high resistance to FHB. Clark [PI 512337, Beau//(65256A1-81/67137B5-16/4/Sullivan/3/Beau//5517B8-5-3-3/Logan)] is a soft red winter wheat variety released from Purdue University, IN, and has high yield potential but is susceptible to FHB 
(Ohm et al., 1988). $F_{1}$ plants from the cross Ning7840/Clark were backcrossed to Clark seven times. Approximately $2000 \mathrm{BC}_{7} \mathrm{~F}_{2}$ plants were screened with flanking markers $\mathrm{Xgwm533}$ (forward primer 5`- AAGGCGAATCAAACGGAATA-3`; reverse 5`ATAAGGCAAACTAAGCGGAA $\quad 3^{`}$ ) and Xgwm493 (forward primer 5`TTCCCATAACTAAAACCGCG-3`; reverse 5`- GCGCCAAAATCAATACCCTT-3`) for Fhb1 and selected $\mathrm{BC}_{7} \mathrm{~F}_{3}$ families were evaluated for FHB resistance in greenhouses. Ten highly resistant lines carrying homozygous Fhb1 and five highly susceptible lines without Fhb1 were further evaluated for FHB resistance and advanced to the $\mathrm{BC}_{7} \mathrm{~F}_{7}$ generation. Five NILs, four most resistant NILs and one most susceptible NIL among the 15 NILs (Clark*7/Ning7840) were finally selected at $\mathrm{BC}_{7} \mathrm{~F}_{7}$ based on phenotypic data and validated for the presence of markers for Fhb1. In addition, these NILs were genotyped with 168 markers distributed across all 21 chromosomes to assess for residual Ning7840 genetic background. A 10- $\mu$ l polymerase chain reaction (PCR) mix contained 1x ammonium sulfate buffer (Bioline, Randolph, MA, USA), 2.5 $\mathrm{mM} \mathrm{MgCl} 2,200 \mu \mathrm{M}$ of each dNTP, $50 \mathrm{nM}$ of forward tailed primer, $100 \mathrm{nM}$ of reverse primer, $50 \mathrm{nM}$ of M13-dye-labeled fluorescent primer, $100 \mathrm{ng}$ DNA, and 1 unit Taq polymerase (Promega, Madison, WI, USA). PCR was carried out in a PTC-200 thermal cycler (Bio-Rad Labs, Hercules, CA, USA) using a touchdown program starting at $96^{\circ} \mathrm{C}$ for $5 \mathrm{~min}$; followed by 5 cycles of $1 \mathrm{~min}$ at $96^{\circ} \mathrm{C}, 5 \mathrm{~min}$ at $68^{\circ} \mathrm{C}$ minus $2^{\circ} \mathrm{C}$ per cycle, and 1 min at $72^{\circ} \mathrm{C}$; 5 cycles of 1 min at $96^{\circ} \mathrm{C}, 2$ min at $58^{\circ} \mathrm{C}$ minus $2^{\circ} \mathrm{C}$ per cycle, and $1 \mathrm{~min}$ at $72^{\circ} \mathrm{C}$; 25 cycles of 1 min at $96^{\circ} \mathrm{C}$, $1 \mathrm{~min}$ at $50^{\circ} \mathrm{C}$, and $1 \mathrm{~min}$ at $72^{\circ} \mathrm{C}$; and a final extension of $5 \mathrm{~min}$ at $72^{\circ} \mathrm{C}$. Primers labeled with FAM, VIC, NED, or PET (Life Technologies, Grand Island, NY) were run as described by Bernardo et al. (2012). Fluorescent dye-labeled PCR products were visualized on an ABI3730 
sequencer (Life Technologies), and were scored using GeneMarker V1.5 (SoftGenetics, State College, PA).

The selected NILs and Clark were evaluated for FHB resistance in both field and greenhouse by single-floret inoculation. F. graminearum conidia (strain GZ 3639, a Kansas field isolate) were produced according to Bai et al. (2000). Plants were grown in the greenhouse at $25^{\circ} \mathrm{C}$ for $12 \mathrm{~h}$ of light and at $18^{\circ} \mathrm{C}$ for $12 \mathrm{~h}$ of darkness. At anthesis, a $10 \mu \mathrm{l}$ ( 1,000 spores) $\mathrm{F}$. graminearum conidiospore suspension was injected into a central spikelet of a spike. Inoculated plants in the greenhouse were enclosed in a plastic chamber with $100 \%$ humidity for $48 \mathrm{~h}$ to initiate FHB infection. Disease rating was done 21 days after inoculation and the proportion of symptomatic spikelets (PSS) per spike was recorded as the percentage of infected spikelets in a spike calculated by dividing the number of infected spikelets by the total number of spikelets in a spike.

Yield trials of NILs and Clark were conducted using a randomized plot design with three replications in 2010 (Manhattan, KS) and 2011 (Manhattan, KS, and Urbana, IL). Analysis of variance was conducted on grain yield and disease severity across locations with SAS version 9.2 (SAS Institute, Cary, NC).

\section{Characteristics}

\section{Genotypes of NILs}

The NILs were fingerprinted using 168 SSR markers across all 21 chromosomes to confirm the presence of Fhb1 and to determine residual genetic background from Ning7840. All four FHBresistant NILs have the 3BS region harboring Fhb1 from Ning7840, and three of them, NILs 78, 80, and 90, also contain a Ning7840 fragment harboring Xbarc108 and Xwmc603 in chromosome 
7A. These two markers are close to a previously identified QTL, Fhb7AC, in Sumai3 (Jayatilake et al., 2011). In addition, NIL80 contains Ning7840 alleles for markers Xgwm147 (1DS) and Xwmc311 (7BL); NIL90 has three Ning7840 fragments in chromosomes 1BL, 1DL, and 2BL; and NIL75 contains four Ning7840 fragments in chromosomes 1DL, 2BL, 7AL, and 7DL. Linked QTLs have not been reported for these markers in Sumai3 or Ning7840 (Liu et al., 2009). The susceptible NIL (NIL98) showed Clark alleles for all markers tested except for Xwmc603. Thus, marker-assisted backcross successfully transferred the Fhb1 into the Clark background.

\section{FHB resistance}

Four resistant and one susceptible NIL (NIL98) were selected for FHB evaluation in both greenhouse and field experiments based on the presence or absence of resistance alleles of Fhb1 flanking markers Xgwm533 and Xgwm493. The mean PSS in all resistant NILs was low, ranging from $7 \%$ to $30 \%$ in the greenhouse and $11 \%$ to $16 \%$ in the fields, whereas PSS for NIL98 (95\% in greenhouse and 53\% in the fields) and Clark (89\% in the greenhouse and 62\% in the fields) were high (Table 1). The difference in PSS between resistant NILs and Clark is significant at $P<$ 0.05 (Table 1), but insignificant between the susceptible NIL and Clark. Although marker data indicated the presence of a fragment from 7A close to a previously identified Fhb7AC in Sumai3, it is unlikely that this QTL contributed to FHB resistance in these NILs, because NIL98 containing the fragment was highly susceptible to FHB and NIL75 without the fragment from Ning7840 showed the highest resistance among the resistant NILs (Table 1).

\section{Agronomic Evaluation}

Results from the 2011 Illinois field trial (Table 2) showed that the NILs headed 1-2 days earlier

or at the same time as Clark, were within a $1.8 \mathrm{~kg} \mathrm{hl}^{-1}$ range of Clark's test weight, and had a height variation of $5 \mathrm{~cm}$. The overall agronomic performance of the resistant NILs was 
comparable to that of Clark, but seeds of resistant NILs had lower DON content than the susceptible NIL and Clark. Grain yields of the NILs were not significantly different $(P=0.278)$ from that of Clark (Table 3); therefore, Fhb1 per se is not associated with undesirable agronomic traits, and the resistant NILs developed in this study should be a good source of Fhb1 for integration of Fhb1 into US winter wheat.

\section{Availability}

Small amounts of seed are available for distribution to wheat breeders, geneticists, and other research personnel on written request to the corresponding author. Seed of the NILs has been deposited in the National Plant Germplasm System, where it will be available for 5 years after the date of publication for research purposes, including development and commercialization of new varieties. Appropriate recognition of the source is requested if these germplasm lines contribute to the development of a new breeding line or variety.

\section{Acknowledgments}

This is contribution number 13-333-J from the Kansas Agricultural Experiment Station, Manhattan, KS, USA. This project is partly funded by the National Research Initiative Competitive Grants CAP project 2011- 68002-30029 from the USDA National Institute of Food and Agriculture and US Wheat and Barley Scab Initiative. Mention of trade names or commercial products in this article is solely for the purpose of providing specific information and does not imply recommendation or endorsement by the U.S. Department of Agriculture. USDA is an equal opportunity provider and employer. 


\section{References}

Bai, G., C. Zhou, C. Qian, and Y. Ge. 1989. A study on scab resistance in new wheat cultivars and advanced breeding lines. Jiangsu Agr. Sci. 7:20-22.

Bai, G.H., F.L. Kolb, G. Shaner, and L.L. Domier. 1999. Amplified fragment length polymorphism markers linked to a major quantitative trait locus controlling scab resistance in wheat. Phytopathology 89:343-348. doi:10.1094/PHYTO.1999.89.4.343.

Bai, G., G. Shaner, and H. Ohm. 2000. Inheritance of resistance to Fusarium graminearum in wheat. Theor. Appl. Genet. 100:1-8.

Bernardo, A.N., R.L. Bowden, M.N. Rouse, M.S. Newcomb, D.S. Marshall, and G. Bai. 2012. Validation of molecular markers for new stem rust resistance genes in U.S. hard winter wheat. Crop Sci. doi:10.2135/cropsci2012.07.0446

Buerstmayr, H., T. Ban, and J.A. Anderson. 2009. QTL mapping and marker-assisted selection for Fusarium head blight resistance in wheat: a review. Plant Breeding. 128:1-26.

Jayatilake, D.V., G.H. Bai, and Y.H. Dong. 2011. A novel quantitative trait locus for Fusarium head blight resistance in chromosome 7A of wheat. Theor. Appl. Genet. 122:1189-1198.

Ohm, H.W., G. Shaner, J.E. Foster, F.L. Patterson, and G. Buechley. 1988. Registration of 'Clark’ Wheat. Crop Sci. 28:6:1032-1032.

Liu, S., M.D. Hall, C.A. Griffey, and A.L. McKendry. 2009. Meta-analysis of QTL associated with Fusarium head blight resistance in wheat. Crop Sci. 49:1955-1968.

Lu Z.Z., and Z.Y. Wang. 1991. Improved resistance in China: Sources of resistance and problems. In: D.A. Sanders, editor, Wheat for the nontraditional warm areas. CIMMYT, DF, Mexico. p. 178-188.

SAS Institute Inc. 2008. SAS/STAT 9.2 User’s Guide. Cary, NC: SAS Institute Inc.

Yu, J.B., G.H. Bai, S.B. Cai, and T. Ban. 2006. Marker-assisted characterization of Asian wheat lines for resistance to Fusarium head blight. Theor. Appl. Genet.113:308-320. 
Table 1. Proportion of symptomatic spikelets in a spike (\% PSS) for near-isogenic lines evaluated under greenhouse (Manhattan, KS) and field conditions (Manhattan, KS, and Urbana, IL).

\begin{tabular}{lclclc}
\hline Lines & GH KS & Field 2010 & Field 2011 & Field 2011 IL & Field mean \\
\hline NIL75 & 7 & 10 & 5 & 16 & $11 \mathrm{a}$ \\
NIL78 & 15 & 14 & 5 & 18 & $13 \mathrm{a}$ \\
NIL80 & 30 & 10 & 5 & 26 & $15 \mathrm{a}$ \\
NIL90 & 13 & 16 & 5 & 27 & $16 \mathrm{a}$ \\
NIL98 & 95 & 77 & 42 & 66 & $53 \mathrm{~b}$ \\
Clark & 89 & 76 & 49 & 66 & $62 \mathrm{~b}$ \\
\hline
\end{tabular}

Means followed by the same letter are not significantly different at $P<0.05$; Dunnett's critical value $=12.5, \mathrm{CV}=35.22 \%$. 
Table 2. Agronomic performance of NILs in 2011 Illinois field trial.

\begin{tabular}{lllcl}
\hline & Test wt (kg/hl) & $\begin{array}{l}\text { Heading date (after } \\
\mathbf{4 / 3 0 )}\end{array}$ & Height (cm) & DON (ppm) \\
\hline NIL75 & 69.37 & 13 & 104.1 & 3.7 \\
NIL78 & 71.69 & 13 & 99.1 & 3.7 \\
NIL80 & 71.04 & 12 & 101.6 & 3.7 \\
NIL90 & 70.27 & 11 & 101.6 & 3.9 \\
NIL98 & 70.79 & 12 & 96.5 & 9.8 \\
Clark & 71.17 & 13 & 99.1 & 9.8 \\
\hline
\end{tabular}


Table 3.Yield (kg/ha) of the near-isogenic lines and Clark evaluated in Manhattan, KS (2010, 2011) and Urbana, IL (2011).

\begin{tabular}{lllll}
\hline & $\mathbf{2 0 1 0} \mathbf{~ K S}$ & $\mathbf{2 0 1 1}$ KS & 2011 IL & Mean \\
\hline NIL75 & 1890.14 & 2707.66 & 2379.36 & 2325.75 \\
NIL78 & 2292.71 & 2737.80 & 2961.69 & 2664.07 \\
NIL80 & 1886.91 & 2527.90 & 2769.02 & 2394.61 \\
NIL90 & 1855.16 & 2517.14 & 2505.84 & 2292.71 \\
NIL98 & 1938.04 & 3201.73 & 2929.40 & 2689.72 \\
Clark & 2011.24 & 2580.65 & 2875.04 & 2488.97 \\
\hline
\end{tabular}

